\title{
UMA PROPOSTA DE SEQUÊNCIA DIDÁTICA SOBRE AGROTÓXICOS FUNDAMENTADA NA ABORDAGEM DE CONTROVÉRSIAS SOCIOCIENTÍFICAS E NA TEORIA DAS SITUAÇÕES DIDÁTICAS
}

\section{A Proposal for a Teaching Sequence on Pesticides Based on the Approach to Socioscientific Issues and the Theory of Didactical Situations}

\author{
Raquel de Abreu Fochesato Quidigno ${ }^{1}$ \\ Carla Krupczak ${ }^{2}$ \\ Joanez Aparecida Aires ${ }^{3}$ \\ Sérgio Camargo ${ }^{4}$ \\ Tania Teresinha Bruns Zimer ${ }^{5}$
}

\begin{abstract}
Resumo: A Teoria das Situações Didáticas é muito utilizada nas pesquisas da Educação Matemática para fundamentar as práticas educativas, mas é quase desconhecida e pouco utilizada nas pesquisas e práticas da área de Educação em Ciências. Nesse sentido, o presente trabalho tem como objetivo propor uma sequência didática sobre agrotóxicos, fundamentada na abordagem de controvérsias sociocientíficas e na Teoria das Situações Didáticas, indicando atividades que tornem as aulas de Química mais críticas e dinâmicas. Este artigo apresenta o processo de construção dessa sequência didática que conta com um total de 14 aulas voltadas ao último ano do Ensino Médio, abordando conteúdos da área de Química (funções orgânicas) por meio da temática do uso de agrotóxicos no Brasil e seus impactos na saúde humana e no meio ambiente. Espera-se com este artigo auxiliar e estimular os professores a utilizarem no planejamento e na aplicação de suas aulas as controvérsias sociocientíficas e a Teoria das Situações Didáticas, uma vez que, pelo uso dessas duas perspectivas teóricas no desenvolvimento das aulas de Química, existe a possibilidade de promover aos estudantes um aprendizado interessante, contextualizado e que possibilita compreender o mundo a sua volta.
\end{abstract}

Palavras-chave: Questões Sociocientíficas. Ensino de Química. Educação em Ciências.

\footnotetext{
${ }^{1}$ Licenciada e bacharela em Química pela Universidade Federal do Paraná (UFPR). Mestra em Educação em Ciências e em Matemática pela UFPR. Doutoranda no Programa de Pós-Graduação em Educação em Ciências e em Matemática da UFPR. ORCID ID: 0000-0001-7991-0776. E-mail: raquel.fochesato@gmail.com

${ }^{2}$ Licenciada e bacharela em Química pela Universidade Federal do Paraná (UFPR). Mestra em Educação em Ciências e em Matemática pela UFPR. Doutoranda no Programa de Pós-Graduação em Educação em Ciências e em Matemática da UFPR. ORCID ID: 0000-0003-0692-2789. E-mail: krupczak@ufpr.br

${ }^{3}$ Doutora em Educação Científica e Tecnológica pela Universidade Federal de Santa Catarina. Professora do Departamento de Química da Universidade Federal do Paraná. ORCID ID: 0000-0002-2925-0826. E-mail: joanez.ufpr@gmail.com

${ }^{4}$ Doutor em Educação para Ciência pela Universidade Estadual Paulista “Júlio de Mesquita Filho". Professor do Departamento de Teoria e Prática de Ensino da Universidade Federal do Paraná. ORCID ID: 0000-0001-87665424. E-mail: s.camargo@ufpr.br

${ }^{5}$ Doutora em Educação pela Universidade de São Paulo. Professora do Departamento de Teoria e Prática de Ensino da Universidade Federal do Paraná. ORCID ID: 0000-0002-9353-7944. E-mail: taniatbz@ufpr.br
} 
Abstract: The Theory of Didactic Situations is widely used in research in Mathematics Education to support educational practices, but it is almost unknown and little used in research and practices in the Science Education area. In this sense, the present study aimed to propose a didactic sequence on pesticides, based on the socioscientific issues approach and the Theory of Didactical Situations, indicating activities that make Chemistry classes more critical and dynamic. This article presents the process of constructing this didactic sequence, which included a total of 14 classes focused on the last year of high school, covering contents in Chemistry area (organic functions) through the theme of the use of pesticides in Brazil and their impacts on human health and in the environment. This article is expected to assist and encourage teachers to use socioscientific issues and Theory of Didactical Situations in the planning and application of their classes. Since with these two theoretical perspectives in the development of Chemistry classes, there is the possibility of promoting to students an interesting, contextualized learning that allows them to understand the world around them.

Keywords: Socioscientific Issues. Chemistry Teaching. Science Education.

\section{Introdução}

A indústria de agrotóxicos surgiu após a Primeira Guerra Mundial, mas só depois da Segunda Guerra Mundial é que seu uso se difundiu pelo mundo. Esta e outras modernizações fundamentaram a chamada Revolução Verde, a qual se dizia ser necessária para garantir a produção de alimentos para toda a população mundial. Várias políticas foram implementadas para estimular a agricultura, sendo o Banco Mundial um dos principais promotores. No Brasil houve a isenção fiscal e tributária para as multinacionais produtoras de agrotóxicos. Além disso, os agricultores só conseguiam ter acesso ao crédito agrícola se comprovassem o uso de insumos químicos (ANDRADE; NUNES-NETO; ALMEIDA, 2018).

O uso de agrotóxicos e a mecanização da agricultura nos países em desenvolvimento, como o Brasil, trouxe alguns problemas, como o êxodo rural, concentração de renda, desvalorização dos trabalhadores rurais, dependência dos insumos químicos, desequilíbrios ambientais, contaminação da água e do ar, degradação do solo e intoxicação de pessoas. Além disso, os agricultores perderam suas raízes socioculturais para adequar-se aos novos meios de produção, voltados para as monoculturas (ANDRADE; NUNES-NETO; ALMEIDA, 2018).

Sendo um assunto tão importante para a sociedade brasileira e que causa tantos impactos no ambiente, é relevante que seja discutido nas escolas. Ademais, é um tema frequente nos meios de comunicação e conhecido dos alunos, sendo uma forma de aproximar os conteúdos da realidade (ANDRADE; NUNES-NETO; ALMEIDA, 2018). E, justamente por causar tantos impactos no ambiente, mas ao mesmo tempo, ter sido amplamente defendido no século $\mathrm{XX}$, o uso de agrotóxicos corresponde a uma controvérsia sociocientífica (CSC). Portanto, permite a abordagem das relações entre ciência, tecnologia e sociedade e de aspectos éticos e morais, contribuindo com uma formação científica, humanística e crítica. As CSC vêm sendo defendidas como forma de promover a alfabetização científica dos alunos (REIS, 2004; ZEIDLER; NICHOLS, 2009; KARISAN; ZEIDLER, 2017; HODSON, 2018; KRUPCZAK; LORENZETTI; AIRES, 2020).

Por conta do exposto, os agrotóxicos já foram tema de outras sequências didáticas propostas por pesquisadores da Educação em Ciências, com os mais variados objetivos (CAVALCANTI et al., 2010; BUFFOLO; RODRIGUES, 2015; LOCATELLI; SANTOS; ZOCH, 2016; MELLO; FONSECA; DUSO, 2018; ANDRADE; NUNES-NETO; ALMEIDA, 2018). No entanto, esta temática nunca foi trabalhada pelo viés da Teoria das Situações 
Didáticas (TSD). Na verdade, esta teoria ainda é bastante desconhecida pelos educadores em ciências, a ponto de não termos encontrado nenhum trabalho da área que a utilize.

A TSD foi desenvolvida por Guy Brousseau, buscando compreender o processo de aprendizagem da Matemática, mas seus fundamentos podem ser utilizados em qualquer área do conhecimento. Em função disso, o objetivo deste artigo é propor uma sequência didática sobre agrotóxicos, fundamentada na abordagem de CSC e na Teoria das Situações Didáticas, indicando atividades que tornem as aulas de Química mais críticas e dinâmicas.

O artigo se inicia com uma breve revisão sobre a TSD e as CSC, que são os aportes teóricos deste trabalho. A partir de tais referências, foi elaborada uma proposta de sequência didática considerando algumas competências trazidas na Base Nacional Comum Curricular (BNCC) para o Ensino Médio na área de Ciências da Natureza. Posteriormente, são apresentadas as etapas da sequência com a indicação das situações didáticas e adidáticas que buscam promover, bem como os estágios da abordagem de CSC presentes. No final, apresentamos nossas conclusões acerca da temática.

\section{Um pouco sobre a teoria das situações didáticas}

A Teoria das Situações Didáticas (TSD) foi desenvolvida por Guy Brousseau para explicar o processo de aprendizagem dos conteúdos matemáticos. Ela se baseia, entre outras coisas, no método socrático, o qual valoriza os conhecimentos prévios dos alunos. Nessa abordagem, Sócrates fez perguntas aos seus discípulos, construindo um diálogo de aprendizagem, que os guiou na busca pelo conhecimento (FREITAS, 2000). Na TSD, é a compreensão das relações entre professor, aluno e meio que permite entender como o conhecimento é apropriado e aprendido. Essa teoria tem como objetivo caracterizar o processo de aprendizagem por meio das chamadas situações didáticas. A percepção destas permite o controle das condições da aula e, por consequência, possibilita melhorar o aprendizado (TEIXEIRA; PASSOS, 2013).

$\mathrm{Na}$ TSD, uma situação é uma interação entre um sujeito e um meio, também conhecido como milieu ${ }^{6}$. As situações didáticas são aquelas que o professor usa para ensinar. Brousseau (2006, p. 214, tradução nossa) declara que "uma situação didática é uma situação em que há uma manifestação direta ou indireta de uma vontade de ensinar - um professor. Em geral, em uma situação didática pode-se identificar pelo menos uma situação-problema e um contrato didático"?.

$\mathrm{Na}$ TSD, o professor não pode ser entendido como um simples transmissor de informações. Ele tem a missão de estruturar, planejar e apresentar problemas que motivem os alunos a buscar novos conhecimentos (BROUSSEAU, 2006, 2009). Assim, o trabalho do professor tem início com a escolha de um bom problema, compatível com as capacidades dos alunos (FREITAS, 2000). É importante que o problema escolhido seja desafiante para o aluno, pois

\footnotetext{
${ }^{6}$ O termo milieu ou milileux em francês é usualmente traduzido como meio. Para Brousseau (2006, p. 9, tradução nossa), "tudo o que atua sobre o aluno ou sobre o qual ele atua é denominado 'milieu". As interações entre o aluno e o milieu levam à aprendizagem.

${ }^{7} \mathrm{O}$ contrato didático mencionado por Brousseau é o que regula a situação didática. Ele é um conjunto de acordos, explícitos ou não, entre o professor e os alunos, que orientam as relações na sala de aula.
} 
A aprendizagem deve ser um processo envolvente para o aluno, que constrói, modifica, enriquece e diversifica esquemas de conhecimento já internalizados a respeito de diferentes conteúdos, a partir do significado e do sentido que pode atribuir a esses conteúdos e ao próprio fato de estar aprendendo (TEIXEIRA; PASSOS, 2013, p. 158).

No momento da apresentação do problema, o professor deve tomar o cuidado de não apresentar as informações em demasia, para que os alunos ainda tenham o que pesquisar. Mas o professor também não pode deixar de apresentar as informações básicas, para que os alunos saibam o que fazer e quais conhecimentos devem aprender. Ou seja, o professor deve encontrar uma situação de equilíbrio entre esses dois extremos (FREITAS, 2000).

É importante lembrar que os alunos possuem concepções prévias, as quais vão se modificando ao longo das experiências vivenciadas. Por isso, os alunos podem ser muito diferentes, em relação aos conhecimentos que possuem (TEIXEIRA; PASSOS, 2013). Os conhecimentos prévios dos alunos são essenciais, pois eles são usados para construir novos saberes. As situações didáticas devem ser organizadas para permitir que os alunos exteriorizem seus conhecimentos prévios. Desse modo, uma sequência didática deve ser estruturada de modo a permitir contradições e desequilíbrios, o que leva o aluno a reestruturar suas concepções iniciais e a aprender (BROUSSEAU, 2006). Assim,

\begin{abstract}
Aceitemos que o significado de um conhecimento origina-se em grande parte do fato de que o aluno o adquire adaptando-se às situações didáticas que lhe são colocadas (devolvidas). Devemos supor também que para cada pedaço de conhecimento existe uma família de situações para dar-lhe um significado apropriado (BROUSSEAU, 2006, p. 42, tradução nossa).
\end{abstract}

Na TSD, considera-se que o aluno aprendeu quando ele consegue usar os novos saberes para resolver outros problemas, sem a ajuda do professor. Estas situações são chamadas por Brousseau $(2006,2009)$ de situações adidáticas, por não terem o controle do professor. O aluno:

[...] terá realmente adquirido esse conhecimento apenas quando for capaz de colocálo em uso por si mesmo em situações que encontrará fora de qualquer contexto de ensino e na ausência de qualquer direção. Tal situação é chamada de situação adidática. Cada item de conhecimento pode ser caracterizado por uma (ou algumas) situações adidáticas que preservam o significado; chamaremos isso de situação fundamental. Mas o aluno não pode resolver nenhuma situação adidática imediatamente; o professor concebe uma que o aluno pode controlar. Essas situações adidáticas dispostas com finalidade didática determinam os saberes ensinados em um dado momento e o significado particular que esses saberes vão ter em virtude das restrições e deformações assim trazidas à situação fundamental (BROUSSEAU, 2006, p. 30, tradução nossa).

Na situação adidática, o aluno tem um esforço próprio e independente, buscando superar seus limites e construir conhecimentos novos. No entanto, inicialmente, se ele não conseguir resolver, pode pedir a orientação do professor e, nesse caso, tem-se novamente uma situação didática (TEIXEIRA; PASSOS, 2013). Mas, no final, "o professor deve sempre ajudar o aluno 
a despir a situação de todos os seus artifícios didáticos o mais rápido possível para deixá-lo com um conhecimento pessoal e objetivo" (BROUSSEAU, 2006, p. 31, tradução nossa).

A noção de situação adidática parece contraditória, porque é algo que não foi definido intencionalmente como uma etapa para ensinar, no entanto, é essencial para o processo pedagógico, pois é quando o aluno torna-se independente. As situações adidáticas são o que há de mais importante no processo de aprendizagem, pois, representam o crescimento e independência do aluno. Tudo que o professor faz deve ser feito pensando em direcionar o aluno para as situações adidáticas. $\mathrm{O}$ aluno precisa ter a oportunidade de se aproximar dos conhecimentos ele mesmo, usando suas próprias técnicas e raciocínios. Numa perspectiva construtivista, o professor precisa estimular o aluno a elaborar novos saberes, a estar sempre se superando, por esforço próprio, que é o processo da situação adidática (FREITAS, 2000).

Os conhecimentos têm diferentes níveis de utilidade e relação com os problemas propostos pelos professores. Por isso, os alunos se relacionam com os saberes de formas variadas. Assim, Brousseau define quatro tipos de situações didáticas e adidáticas, as quais são fortemente entrelaçadas (FREITAS, 2000):

a) Situações de ação: ocorrem quando o aluno está empenhado em buscar respostas para um problema por meio de ações imediatas, produzindo um conhecimento mais operacional. Nestas situações há um predomínio de aspectos experimentais, o aluno apresenta formas de solucionar o problema, mas, não sabe explicar os fundamentos teóricos que o guiam e nem se preocupa em conhecê-los.

b) Situações de formulação: ocorrem quando o aluno utiliza informações teóricas e consegue estabelecer alguns esquemas teóricos simples para explicar partes do problema. Mas o saber ainda não é usado para justificar e controlar as ações, e a linguagem utilizada não é a mais adequada cientificamente.

c) Situações de validação: ocorrem quando o aluno busca validar os conhecimentos que usa, por meio de algum tipo de prova, com o objetivo de convencer o professor ou os colegas de suas alegações. Nesses casos, o aluno utiliza a linguagem adequada para apresentar as explicações.

d) Situações de institucionalização: ocorrem quando o professor indica aos alunos a universalidade dos conhecimentos usados para resolver o problema. Os saberes construídos na resolução de um problema não são únicos dele, podendo ser utilizados em outros problemas. Como os conhecimentos produzidos nas situações adidáticas são muito amplos, faz-se necessária uma fase de institucionalização do saber, realizada pelo professor. Nesse momento, o professor dá os "retoques finais", para garantir que os conhecimentos produzidos pelo aluno estão de acordo com o que é aceito científica e socialmente (FREITAS, 2000).

Assim, na TSD o trabalho pedagógico não consiste em simples transmissão de conhecimentos, mas em uma reconstrução do saber, que ocorre por meio de situações didáticas e adidáticas, em que o professor é um mediador (FREITAS, 2000; BROUSSEAU, 2006).

Apesar de ser muito utilizada pelos pesquisadores da Educação Matemática, a TSD é quase desconhecida pelos pesquisadores e professores de Ciências, não tendo sido encontrados artigos da área em que conste tal teoria como fundamentação teórica. Em função disso, este artigo propõe usar a TSD para fundamentar uma sequência didática para o Ensino de Química, pois, dada a abrangência da teoria, ela pode contribuir com a compreensão dos processos de ensino e aprendizagem em outras disciplinas além da matemática, possibilitando aos professores uma fundamentação teórica que auxilie na preparação de suas aulas, considerando 
os conhecimentos prévios dos alunos e valorizando situações didáticas e adidáticas em sala de aula.

O desenvolvimento de sequências didáticas que consideram a TSD e as controvérsias sociocientíficas (CSC) contribui para a área de Ensino de Química, ao proporcionar uma alternativa para os professores elaborarem aulas e/ou sequências didáticas com relevância social, científica, ecológica, econômica e tecnológica, trazendo aos alunos um entendimento contextualizado de conteúdos a serem abordados nas aulas de Química. Cabe ressaltar aqui que a TSD pode ser pensada de maneira a abranger também outras áreas do conhecimento.

\section{Um pouco sobre as controvérsias sociocientíficas}

As controvérsias sociocientíficas (CSC) podem ser definidas como "dilemas da sociedade com vínculos conceituais, processuais ou tecnológicos à ciência" (SADLER; ZEIDLER, 2004, p. 5, tradução nossa). Tais dilemas envolvem aspectos científicos, possibilitam analisar as escolhas envolvidas em diferentes âmbitos (mundial, nacional, local) e geram reflexos expressivos na sociedade. Alguns exemplos de CSC são: uso de agrotóxicos, modificação genética de plantas (transgênicos), manipulação genética de seres humanos, uso de combustíveis não derivados de petróleo, eutanásia, entre outros.

As CSC não podem ser resolvidas de imediato, apenas analisando dados técnicos, pelo contrário, precisam de uma análise mais global, considerando aspectos sociais, ambientais, culturais, políticos, financeiros, de saúde, entre outros (KRUPCZAK, 2019). Por não possuírem uma única solução correta, as CSC são bastante diferentes dos problemas normalmente resolvidos nas aulas de ciências, os quais costumam ter uma resposta certa (REIS, 2004).

As CSC são bastante interessantes para os alunos e uma forma de aproximar os conteúdos da realidade (ZEIDLER; NICHOLS, 2009). Por conta disso, a abordagem de CSC também é eficaz na aprendizagem dos conteúdos científicos, facilitando a compreensão dos conceitos. Além disso, elas envolvem os alunos em processos de discussão, argumentação, raciocínio lógico, análise de dados e tomada de decisão, habilidades essenciais para todo cidadão (EASTWOOD et al., 2012).

A abordagem de CSC tem potencial para o desenvolvimento de diversas habilidades sociais e cognitivas importantes, como as descritas no Quadro 1.

Quadro 1 - Habilidades que podem ser promovidas pela abordagem de CSC

\begin{tabular}{|l|l|}
\hline Habilidades sociais & $\begin{array}{l}\text { Comunicação, trabalho cooperativo, debater a fundamentação das opiniões, apoio entre } \\
\text { os indivíduos, saber escutar a opinião do outro, autoestima... }\end{array}$ \\
\hline $\begin{array}{l}\text { Habilidades } \\
\text { cognitivas }\end{array}$ & $\begin{array}{l}\text { Poder de argumentação, capacidade de analisar e explicar, pesquisa e recolha de } \\
\text { informações, detecção de incoerências em dados, avaliação da credibilidade das fontes, } \\
\text { pensar de forma crítica e formular opiniões próprias, reavaliar as próprias posições, } \\
\text { construção de hipóteses, independência intelectual, compreender as diversas dimensões } \\
\text { de uma situação... }\end{array}$ \\
\hline
\end{tabular}

Fonte: Krupczak (2019, p. 71).

A abordagem de CSC também vem sendo defendida por permitir a compreensão da natureza da ciência de forma contextualizada (WALKER; ZEIDLER, 2007; EASTWOOD et al., 2012; LEDERMAN; ANTINK; BARTOS, 2014; KARISAN; ZEIDLER, 2017) e por 
facilitar o desenvolvimento da alfabetização científica (REIS, 2004; ZEIDLER; NICHOLS, 2009; KARISAN; ZEIDLER, 2017; HODSON, 2018; KRUPCZAK; LORENZETTI; AIRES, 2020).

Hodson (2018) propõe que a abordagem de CSC siga quatro estágios fundamentais:

\begin{abstract}
- Estágio 1: a apreciação dos impactos sociais e ambientais da mudança científica e tecnológica e o reconhecimento de que a ciência e a tecnologia são, até certo ponto, culturalmente determinadas;

- Estágio 2: o reconhecimento de que as decisões sobre o desenvolvimento científico e tecnológico são tomadas na busca de interesses particulares e que benefícios para alguns podem ser às custas de outros. $\mathrm{O}$ reconhecimento de que os desenvolvimentos em ciência e tecnologia são inextricavelmente ligados à distribuição de riqueza e poder;

- Estágio 3: abordar a controvérsia, esclarecer valores, resolver dilemas éticos, formular e desenvolver suas próprias opiniões e justificá-las através da discussão e do argumento;

- Estágio 4: preparar-se para agir e agir sobre questões sociocientíficas e ambientais (HODSON, 2018, p.35).
\end{abstract}

Com essa abordagem pretende-se que os alunos possam colocar em prática, por meio de uma ação sociopolítica ${ }^{8}$, os conhecimentos adquiridos durante todo o processo. Para isso, o professor tem que atuar em todas as etapas como mediador do processo de aprendizagem, mostrando caminhos para que os alunos consigam compreender de maneira clara as questões envolvidas no estudo de determinada CSC (HODSON, 2018). Segundo Zeidler e Nichols (2009), os professores devem sempre questionar os alunos acerca das suas posições, os colocando em processo de reflexão. Eles devem guiar as discussões para que perpassem diferentes linhas de argumento, para que os alunos não se limitem às suas ideias.

Hodson (2018) lembra que é importante que o professor use fontes de informação variadas, com linguagens diferentes, como notícias, vídeos, imagens, músicas, relatos reais, poesias, entre outros. Sadler, Foulk e Friedrichsen (2017) destacam a importância do uso das tecnologias da informação e comunicação para pesquisar sobre as CSC na web. Afinal, tratamse de temas atuais e dinâmicos, novas informações sempre estão surgindo. Por isso, fontes mais estáticas, como livros didáticos que, geralmente, são utilizados por vários anos nas escolas, podem conter textos/informações desatualizados.

\title{
4 Os momentos da sequência didática sobre o uso de agrotóxicos
}

A presente sequência didática utiliza os quatro estágios propostos por Hodson (2018) e engloba situações didáticas e adidáticas, buscando levar aos alunos um estudo contextualizado e problematizado do uso de agrotóxicos no Brasil e seus impactos na saúde humana e no meio ambiente.

O conteúdo pensado para ser abordado dentro da temática proposta foi funções orgânicas que, usualmente, é um conteúdo abordado no último ano do Ensino Médio na disciplina de Química. Vale ressaltar que a presente proposta poderia ser repensada, a fim de

\footnotetext{
8 Ações sociopolíticas são atitudes que qualquer cidadão pode fazer para ajudar a resolver ou amenizar um problema. São exemplos de ação sociopolítica: criar páginas em redes sociais para divulgar informações para a população, separar e reciclar o lixo, limpar um rio poluído, plantar árvores, realizar trabalhos voluntários em projetos sociais, criar grupos de estudo e pesquisa, escrever para jornais, entre outros (HODSON, 2018).
} 
proporcionar uma abordagem interdisciplinar para além do trabalho com os conhecimentos da área de Química.

Com relação ao currículo, ao se observar a BNCC, percebe-se que as habilidades estimuladas pela abordagem de CSC em sala de aula vão ao encontro das três competências para o Ensino Médio na área de Ciências da Natureza e suas Tecnologias, como indica o Quadro 2 (BNCC, 2017).

Quadro 2 - Competências e habilidades da BNCC que podem ser desenvolvidas na proposta da sequência didática.

\begin{tabular}{|c|c|}
\hline $\begin{array}{l}\text { Competência } \\
1\end{array}$ & $\begin{array}{l}\text { Analisar fenômenos naturais e processos tecnológicos, com base nas interações e relações } \\
\text { entre matéria e energia, para propor ações individuais e coletivas que aperfeiçoem processos } \\
\text { produtivos, minimizem impactos socioambientais e melhorem as condições de vida em âmbito } \\
\text { local, regional e global (BNCC, 2017, p. 553). }\end{array}$ \\
\hline \multirow{2}{*}{$\begin{array}{l}\text { Habilidades } \\
\text { vinculadas à } \\
\text { competência } 1\end{array}$} & $\begin{array}{l}\text { (EM13CNT104) Avaliar os benefícios e os riscos à saúde e ao ambiente, considerando a } \\
\text { composição, a toxicidade e a reatividade de diferentes materiais e produtos, como também o } \\
\text { nível de exposição a eles, posicionando-se criticamente e propondo soluções individuais e/ou } \\
\text { coletivas para seus usos e descartes responsáveis (BNCC, 2017, p. 555). }\end{array}$ \\
\hline & $\begin{array}{l}\text { (EM13CNT105) Analisar os ciclos biogeoquímicos e interpretar os efeitos de fenômenos } \\
\text { naturais e da interferência humana sobre esses ciclos, para promover ações individuais e/ ou } \\
\text { coletivas que minimizem consequências nocivas à vida (BNCC, 2017, p. 555). }\end{array}$ \\
\hline $\begin{array}{l}\text { Competência } \\
2\end{array}$ & $\begin{array}{l}\text { Analisar e utilizar interpretações sobre a dinâmica da Vida, da Terra e do Cosmos para elaborar } \\
\text { argumentos, realizar previsões sobre o funcionamento e a evolução dos seres vivos e do } \\
\text { Universo, e fundamentar e defender decisões éticas e responsáveis. (BNCC, 2017, p. 553). }\end{array}$ \\
\hline $\begin{array}{l}\text { Habilidades } \\
\text { vinculadas à } \\
\text { competência } 2\end{array}$ & $\begin{array}{l}\text { (EM13CNT206) Discutir a importância da preservação e conservação da biodiversidade, } \\
\text { considerando parâmetros qualitativos e quantitativos, e avaliar os efeitos da ação humana e } \\
\text { das políticas ambientais para a garantia da sustentabilidade do planeta (BNCC, 2017, p. 557). }\end{array}$ \\
\hline $\begin{array}{l}\text { Competência } \\
3\end{array}$ & $\begin{array}{l}\text { Investigar situações-problema e avaliar aplicações do conhecimento científico e tecnológico e } \\
\text { suas implicaços no mundo, utilizando procedimentos e linguagens próprios das Ciências da } \\
\text { Natureza, para propor soluções que considerem demandas locais, regionais e/ou globais, e } \\
\text { comunicar suas descobertas e conclusões a públicos variados, em diversos contextos e por } \\
\text { meio de diferentes mídias e tecnologias digitais de informação e comunicação (BNCC, 2017, } \\
\text { p. 539). }\end{array}$ \\
\hline \multirow{2}{*}{$\begin{array}{l}\text { Habilidades } \\
\text { vinculadas à } \\
\text { competência } 3\end{array}$} & $\begin{array}{l}\text { (EM13CNT302) Comunicar, para públicos variados, em diversos contextos, resultados de } \\
\text { análises, pesquisas e/ou experimentos, elaborando e/ou interpretando textos, gráficos, tabelas, } \\
\text { símbolos, códigos, sistemas de classificação e equações, por meio de diferentes linguagens, } \\
\text { mídias, tecnologias digitais de informação e comunicação (TDIC), de modo a participar e/ou } \\
\text { promover debates em torno de temas científicos e/ou tecnológicos de relevância sociocultural } \\
\text { e ambiental (BNCC, 2017, p. 559). }\end{array}$ \\
\hline & $\begin{array}{l}\text { (EM13CNT303) Interpretar textos de divulgação científica que tratem de temáticas das } \\
\text { Ciências da Natureza, disponíveis em diferentes mídias, considerando a apresentação dos } \\
\text { dados, tanto na forma de textos como em equações, gráficos e/ou tabelas, a consistência dos } \\
\text { argumentos e a coerência das conclusões, visando construir estratégias de seleção de fontes } \\
\text { confiáveis de informações (BNCC, 2017, p. 559). }\end{array}$ \\
\hline
\end{tabular}


(EM13CNT304) Analisar e debater situações controversas sobre a aplicação de conhecimentos da área de Ciências da Natureza (tais como tecnologias do DNA, tratamentos com células-tronco, neuro tecnologias, produção de tecnologias de defesa, estratégias de controle de pragas, entre outros), com base em argumentos consistentes, legais, éticos e responsáveis, distinguindo diferentes pontos de vista (BNCC, 2017, p. 559).

Fonte: Autores (2020).

Por exemplo, as habilidades EM13CNT104 e EM13CNT105 são trabalhadas logo nos primeiros momentos dessa proposta de sequência didática, quando os estudantes são instigados a pesquisar sobre o uso, toxicidade e consequências dos agrotóxicos. Já a habilidade EM13CNT206 é desenvolvida quando se sugere que o professor peça aos alunos para que pensem em formas alternativas de produção de alimentos, que não envolvam o uso de agrotóxicos. Por fim, as habilidades EM13CNT302 e EM13CNT303 são especialmente trabalhadas no momento da ação sociopolítica, que é a última etapa desta sequência didática.

A proposta dessa sequência didática foi pensada para ser realizada em um total de 14 aulas, de 50 minutos cada, além de um período para uma visita técnica. Entretanto, ressaltamos que o número de aulas pode ser adaptado de acordo com as dificuldades dos alunos e as possibilidades da escola.

A proposta de sequência didática a seguir pode ser pensada em nove momentos, os quais compõem os quatro estágios de Hodson (2018): problematização inicial; pesquisa inicial; aprendizagem de conceitos científicos fundamentais; finalização da pesquisa; retomada do conteúdo, apresentação e discussão das pesquisas, discussão de alternativas, visita técnica e ação sociopolítica.

\subsection{Estágio 1: compreender os impactos da ciência e tecnologia}

\subsubsection{Momento 1: problematização inicial}

A sequência didática começa com a leitura de notícias sobre algum problema relacionado com o uso de agrotóxicos. Uma opção é a "nuvem de gafanhotos" que estava se aproximando do território brasileiro em 2020. Outra situação que poderia ser usada é a da diminuição das populações de abelhas. Para isso, devem ser selecionados previamente textos confiáveis, como de jornais tradicionais que possuem verificação das informações, e, se possível, que abordem os problemas partindo de pontos de vista distintos.

Nesse primeiro momento da sequência acontece também a visualização de um documentário, que apresenta algumas informações sobre o uso de agrotóxicos. Recomenda-se um trecho de aproximadamente 35 minutos (o trecho entre 00:04:40 e 00:40:59) do documentário O veneno está na mesa, de Silvio Tendler"

A partir da leitura e da visualização do documentário, o professor poderá promover a discussão com os alunos a partir de algumas perguntas disparadoras como, por exemplo: Vocês consomem produtos tradicionais ou orgânicos? Vocês observam os rótulos dos produtos quando vão às compras para ver se possuem transgênicos? O que vocês acham que aconteceria se as abelhas sumirem? Qual o impacto do uso de agrotóxicos na saúde? Quais as vantagens do uso

\footnotetext{
${ }^{9}$ Documentário na íntegra disponível em https://www.youtube.com/watch?v=8RVAgD44AGg
} 
de agrotóxicos? Quais as consequências do uso de agrotóxicos? Quais são as pessoas mais afetadas pelos agrotóxicos?

Esse primeiro momento, recomendado para ser realizado em duas aulas, possibilita ao aluno uma situação didática de ação (BROUSSEAU, 2006), em que seriam considerados os conhecimentos prévios dos alunos sobre a temática. Busca-se também promover o entendimento dos alunos sobre os impactos sociais, ambientais e culturais do uso de agrotóxicos, bem como reconhecer as motivações que levam ao uso de tais insumos químicos. Ou seja, a competência 1 da BNCC para a área de Ciências da Natureza e suas Tecnologias é abordada (Quadro 2). Assim, é possível desenvolver o primeiro estágio da abordagem de CSC sugerido por Hodson (2018).

\subsubsection{Momento 2: pesquisa inicial}

O segundo momento da sequência didática ocorre em uma aula e com a turma dividida em equipes. A cada grupo será atribuído um tipo de agrotóxico específico para que pesquisem aspectos como: estrutura química, para que são utilizados e em quais lavouras, onde são permitidos, onde são proibidos e o porquê, nível de toxicidade, qual é a empresa produtora e de que país ela é, se essa empresa tem algum projeto social ou ambiental que indique responsabilidade, notícias sobre a empresa e o agrotóxico, entre outras informações que os alunos considerem relevantes. Para a realização da pesquisa, será necessário levar os alunos ao laboratório de informática da escola. Essa é uma atividade que também pode ser atribuída como tarefa de casa, caso todos os alunos tenham acesso à internet nas suas residências. A lista de agrotóxicos que podem ser utilizados na pesquisa e o modelo do roteiro que pode ser utilizado pelos alunos encontram-se anexados ao artigo (Apêndice A).

A ideia é que esse momento de pesquisa inicial possibilite uma situação adidática, na qual os alunos irão formular hipóteses e esquemas teóricos simples sobre a temática proposta, sem a interferência específica do professor (BOUSSEAU, 2006). Os alunos terão um primeiro contato com as estruturas químicas dos agrotóxicos, criando as primeiras relações entre a estrutura e as propriedades químicas. Além disso, começarão a perceber algumas questões sociais, econômicas, políticas, ambientais, entre outras, que são relevantes para a temática.

A iniciativa da pesquisa permite também que os alunos analisem as diferentes fontes de informação, buscando verificar de maneira crítica os conteúdos encontrados. Dessa forma, exercita-se a habilidade de reconhecer e diferenciar fontes confiáveis de informação de fontes duvidosas, que promovem eventuais fake news, capacidade considerada muito importante para os cidadãos (REIS, 2004; SADLER; ZEIDLER, 2004; SADLER et al., 2017). Assim, a competência 3 da BNCC para a área de Ciências da Natureza e suas Tecnologias é trabalhada com os estudantes (Quadro 2).

\subsubsection{Momento 3: aprendizagem de conceitos científicos fundamentais}

Esse é o ponto da sequência em que ocorre outra situação didática, programada para ocupar duas aulas. O professor vai abordar os conceitos químicos fundamentais relacionados ao conteúdo, como a identificação das funções orgânicas, suas características e nomenclaturas, podendo usar os agrotóxicos como contexto. Pesquisa de Eastwood et al. (2012) indica que quando os conteúdos científicos são ensinados no contexto das CSC, os alunos aprendem melhor os conceitos e sabem usá-los em situações do cotidiano mais facilmente. 
Com esses novos conhecimentos, os alunos poderão retornar para o processo de pesquisa com mais informações e poderão elaborar novas ideias, teorias e hipóteses sobre a questão do uso dos agrotóxicos.

4.2 Estágio 2: entender que a ciência e tecnologia são afetadas por questões sociais, políticas, éticas, econômicas, entre outras

\subsubsection{Momento 4: finalização da pesquisa}

Buscando a promoção de mais uma situação adidática, será proposto aos grupos que retornem ao laboratório de informática e continuem a pesquisa sobre os agrotóxicos iniciada no momento 2. O professor deve incentivar os alunos a buscarem informações sobre as empresas produtoras de agrotóxicos e a saberem se elas participam de algum tipo de isenção fiscal ou outros incentivos governamentais. Eles também devem pesquisar um pouco sobre a história dos agrotóxicos, tentando identificar porque eles se tornaram tão comuns nas plantações. Ou seja, espera-se que os alunos comecem a entender que fatores econômicos, políticos, sociais, entre outros, afetam as decisões sobre questões científicas e tecnológicas. Desta forma, o segundo estágio da abordagem de CSC começa a ser trabalhado.

Durante esse momento, podem também ocorrer situações de validação (BOUSSEAU, 2009), em que os alunos buscam validar os conhecimentos encontrados no processo de pesquisa com o professor ou com os próprios colegas de equipe. Propõe-se que seja utilizada uma aula para esta tarefa.

\subsubsection{Momento 5: retomada do conteúdo}

Aqui o professor irá, em uma aula, retomar o conteúdo abordado no momento 3, revisando e tirando dúvidas. Sugere-se a resolução de alguns exercícios de vestibulares e do Exame Nacional do Ensino Médio sobre a temática dos agrotóxicos e das funções orgânicas. Como a sequência é feita para alunos do último ano do Ensino Médio, é importante ter um tempo para pensar nas provas de ingresso ao Ensino Superior.

\subsection{Estágio 3: entender as controvérsias por meio da discussão e argumentação}

\subsubsection{Momento 6: apresentação e discussão das pesquisas}

Nesse momento, os alunos irão apresentar os achados e resultados de suas pesquisas sobre os agrotóxicos. Devem ser discutidas as relações ciência, tecnologia e sociedade percebidas pelos alunos e também questões relativas à estrutura e às características químicas desses compostos. Será um momento de troca entre os pares, bem como de reflexão e de argumentação sobre aspectos específicos quanto ao uso dos agrotóxicos.

Portanto, o terceiro estágio da abordagem de CSC, proposto por Hodson (2018), começa a ser trabalhado. Além disso, ocorre uma situação didática de validação e até de institucionalização, se o professor optar por isso (BOUSSEAU, 2006). Recomenda-se o uso de duas aulas para esse momento. 


\subsubsection{Momento 7: discussão de alternativas}

Pensando no uso das CSC em sala de aula, faz-se necessária a promoção de um momento de análise e reflexão sobre os aspectos envolvidos no uso de agrotóxicos, buscando possíveis alternativas ou até mesmo soluções para o problema envolvendo estes tipos de insumos agrícolas. Para iniciar as discussões, será apresentado um trecho do documentário $O$ veneno está na mesa 2 (sugere-se o trecho entre 00:28:27 e 00:58:53) ${ }^{105}$.

Também se recomenda a leitura de reportagens sobre outras formas de plantio que não utilizam agrotóxicos. Dessa forma, espera-se iniciar a discussão sobre maneiras alternativas de plantio. O professor pode realizar perguntas, buscando motivar a discussão, como: vocês já conheciam técnicas diferentes de plantio? Conhecem outra que não foi mencionada aqui? Já fizeram uma horta em casa? Esse momento, realizado em duas aulas, estimula situações didáticas de ação e formulação e continua a promover o terceiro estágio da abordagem de CSC. Além disso, é um momento para fomentar a competência 3 da BNCC para a área de Ciências da Natureza e suas Tecnologias.

\subsection{Estágio 4: agir sobre a controvérsia sociocientífica}

\subsubsection{Momento 8: visita técnica}

Nesse momento da sequência didática, propõe-se que o professor leve a turma para uma visita técnica a uma horta urbana orgânica ou a uma fazenda sustentável, que utilize técnicas de plantio sem agrotóxicos. Nessa visita técnica pretende-se que os alunos interajam com os responsáveis por esses processos de plantio e visualizem na prática como são realizadas técnicas sustentáveis. Tal interação será rica para o próximo momento da sequência, em que ocorre a realização da ação sociopolítica.

Segundo Hodson (2018), antes de executar uma ação sociopolítica, os alunos precisam aprender sobre ela. Isso pode ser feito por meio de entrevistas, estudos de caso, visitas, entre outros. Assim, os alunos ficam mais motivados para realizar a sua ação e podem saber o que deu certo ou não em outras situações parecidas.

\subsubsection{Momento 9: ação sociopolítica}

No último momento da sequência didática, busca-se promover uma situação didática de institucionalização, na qual os conhecimentos trabalhados durante a sequência possam ser usados. Propõe-se que os alunos construam uma horta orgânica na escola, gravem vídeos instrutivos sobre a temática e os divulguem para a escola e a sociedade em geral. Nesse momento, ocorrem ações sociopolíticas que impactam não só os alunos, mas toda a comunidade em que estão inseridos.

Em seguida, os alunos serão organizados em grupos e, para que todos possam participar das três tarefas, será realizado um sistema de rodízio e a cada aula um grupo dará continuidade a uma tarefa em específico. A primeira tarefa será a construção de uma horta orgânica na escola, buscando produzir uma fonte de alimentos saudáveis que poderão ser utilizados na merenda da escola ou mesmo doados para famílias da comunidade. Caso a escola não possua um espaço que possa ser utilizado para a horta, pode-se optar por fazer os plantios em vasos feitos de pneus

${ }^{105}$ Documentário na íntegra disponível em https://www.youtube.com/watch?v=fyvoKljtvG4 
velhos, baldes quebrados, garrafas PET ou qualquer outro material reciclado. A segunda tarefa será a gravação do processo de construção da horta e de vídeos instrucionais sobre os agrotóxicos e formas alternativas de plantio. A terceira tarefa será a divulgação do material gravado em diferentes plataformas digitais (site da escola, YouTube, Facebook, Instagram, TikTok, entre outros). Assim, finaliza-se o quarto estágio da abordagem de CSC e a sequência didática. Recomenda-se que este momento seja realizado em três aulas.

A sequência didática proposta foi construída pensando em um processo de avaliação contínua, que levará em consideração o desenvolvimento dos alunos ao longo das aulas. Dessa maneira, a avaliação possibilita continuar com ações em sala de aula e repensar propostas colocadas em prática a partir de um arcabouço teórico (LUCKESI, 2000). Assim, desde o primeiro momento da sequência, o professor poderá compreender o entendimento prévio dos alunos sobre a temática dos agrotóxicos e seus impactos no ambiente e na saúde humana.

Para atribuição de nota, pode-se utilizar uma avaliação somativa (TARAS, 2010), ou seja, utilizando diferentes instrumentos para compor a nota final da proposta. Para tal, podem ser considerados a apresentação dos alunos sobre a pesquisa, a entrega de um relatório escrito com os resultados da pesquisa, a entrega de exercícios realizados em sala e o comprometimento na realização das ações sociopolíticas.

Cabe ressaltar que, ao mesmo tempo em que pode ser realizada a avaliação somativa, existe a recepção pelo professor de um feedback do seu trabalho e do processo de aprendizagem de seu aluno. Dessa maneira, é possível identificar características de um processo formativo de avaliação nesse contexto. Percebe-se então que a avaliação somativa e formativa estão longe de ser dois processos totalmente distintos, mas sim podem ser complementares (TARAS, 2010).

\section{Considerações Finais}

O objetivo deste artigo foi propor uma sequência didática sobre agrotóxicos, fundamentada na Teoria das Situações Didáticas e na abordagem de CSC, indicando atividades que tornem as aulas de Química mais críticas e dinâmicas. Assim, buscamos subsidiar os professores com uma proposta de ensino fundamentada e preparada para desenvolver algumas habilidades importantes para os alunos, como argumentação, pesquisa de informação, ativismo, discussão e compreensão de fatores que afetam a ciência e tecnologia, pensamento crítico, entre outros. Além disso, a sequência aproxima os conteúdos químicos da realidade dos alunos. A proposta também possibilita a ocorrência de situações didáticas e adidáticas de vários tipos, o que pode facilitar a aprendizagem e o desenvolvimento da autonomia dos alunos.

Segundo Reis (2004), apesar de muitos professores reconhecerem as potencialidades de aulas centradas em CSC, eles acabam não utilizando tal abordagem por não saberem como organizar uma aula nesse formato, seja por falta de tempo ou de formação adequada. Por isso, os professores sentem falta de sequências didáticas e outros materiais que possam auxiliá-los. Nesse sentido, este artigo surge para tentar ajudar a preencher esta lacuna.

Outros exemplos de sequências didáticas sobre CSC construídas para serem usadas por professores podem ser encontradas no livro Questões Sociocientíficas: fundamentos, propostas de ensino e perspectivas para ações sociopolíticas (CONRADO; NUNES-NETO, 2018). Por exemplo, Conrado et al. (2018) propõem uma sequência sobre o declínio dos polinizadores, a qual é voltada para os conteúdos de Biologia e pode ser aplicada ao Ensino Médio ou ao Ensino Superior. Os autores apresentam um caso fictício de envenenamento das abelhas de um apicultor e o usam para iniciar as discussões com os estudantes. Andrade et al. (2018) apresentam um exemplo de proposta que também aborda os agrotóxicos e é recomendada pelos 
autores para o Ensino Fundamental ou o Ensino Médio. Os pesquisadores utilizam o caso da contaminação de um trabalhador rural por agrotóxicos para motivar as discussões e trabalhar os conceitos de agroecologia. Martins et al. (2018) criaram uma sequência didática que versa sobre a doença de chagas e foi pensada para o Ensino Médio. Os autores propõem analisar o caso de uma pessoa que possui a doença de chagas, mostrando sua história. Por fim, Santos, Conrado e Nunes-Neto (2018) discutem a poluição hídrica em uma proposta didática produzida para ser aplicada para o Ensino Fundamental, com base em histórias contadas por pessoas idosas.

\section{Referências}

ANDRADE, M. A. S.; NUNES-NETO, N.; ALMEIDA, R. O. Uso de agrotóxicos: uma questão sociocientífica para o ensino médio. In: CONRADO, D. M.; NUNES-NETO, N. (org.). Questões sociocientíficas: fundamentos, propostas de ensino e perspectivas para ações sociopolíticas. Salvador: EDUFBA, 2018, p. 121-144.

BRASIL. Base Nacional Comum Curricular: Educação é a Base. Brasília, MEC/CONSED/UNDIME, 2017. Disponível em: <http://basenacionalcomum.mec.gov.br/images/BNCC_publicacao.pdf>. Acesso em: 27 ago. 2020.

BROSSEAU, G. A cultura matemática é um instrumento para a cidadania. [Entrevista concedida a] Thais Gurgel. Nova Escola, São Paulo, n. 288, p. 1-6, 1 dez. 2009.

BROUSSEAU, G. Theory of didactical situations in mathematics: Didactique des mathématiques, 1970-1990. New York: Springer Science \& Business Media, 2006

BUFFOLO, A. C. C.; RODRIGUES, M. A. Agrotóxicos: uma proposta socioambiental reflexiva no ensino de Química sob a perspectiva CTS. Investigações em Ensino de Ciências, v. 20, n. 1, p. 01-14, 2015.

CAVALCANTI, J. A.; FREITAS, J. C. R.; MELO, A. C. N.; FILHO, J. R. F. Agrotóxicos: uma temática para o ensino de Química. Química nova na escola, v. 32, n. 1, p. 31-36, 2010.

CONRADO, D.; NUNES-NETO, N. Questões sociocientíficas: fundamentos, propostas de ensino e perspectivas para ações sociopolíticas. Salvador: EDUFBA, 2018.

CONRADO, D. M.; NUNES-NETO, N.; VIANA, B. F.; EL-HANI, C. N. Declínio de polinizadores como questão sociocientífica no ensino de biologia. In: CONRADO, D. M.; NUNES-NETO, N. (org.). Questões sociocientíficas: fundamentos, propostas de ensino e perspectivas para ações sociopolíticas. Salvador: EDUFBA, 2018, p. 145-172.

EASTWOOD, J. L.; SADLER, T. D.; ZEIDLER, D. L.; LEWIS, A.; AMIRI, A.; APPLEBAUM, S. Contextualizing nature of science instruction in socioscientific issues. International Journal of Science Education, v. 34, n. 15, p. 2289-2315, 2012

FREITAS, J. L. M. Situações didáticas. In: MACHADO, S. D. A. et al. Educação matemática: uma introdução. São Paulo: EDUC, 2000. p. 65-88. 
HODSON, D. Realçando o papel da ética e da política na educação científica: algumas considerações teóricas e práticas sobre questões sociocientíficas. In: CONRADO, D. M.; NUNES-NETO, N. (org.). Questões sociocientíficas: fundamentos, propostas de ensino e perspectivas para ações sociopolíticas. Salvador: EDUFBA, 2018. Cap. 1. p. 27-57.

KARISAN, D.; ZEIDLER, D. L. Contextualization of nature of science within the socioscientific issues framework: A review of research. International Journal of Education in Mathematics, Science and Technology, v. 5, n. 2, p. 139-152, 2017

KRUPCZAK, C. Natureza da ciência nas pesquisas sobre controvérsias sociocientíficas: o estado do conhecimento no contexto brasileiro. 2019. $171 \mathrm{f}$. Dissertação (Mestrado) - Curso de Programa de Pós-Graduação em Educação em Ciências e em Matemática, Universidade Federal do Paraná, Curitiba, 2019.

KRUPCZAK, C.; LORENZETTI, L.; AIRES, J. A. Controvérsias sociocientíficas como forma de promover os eixos da alfabetização científica. Tear: Revista de Educação, Ciência e Tecnologia, v. 9, n. 1, p. 1-20, 2020.

LEDERMAN, N. G.; ANTINK, A.; BARTOS, S. Nature of science, scientific inquiry, and socio-scientific issues arising from genetics: A pathway to developing a scientifically literate citizenry. Science \& Education, v. 23, n. 2, p. 285-302, 2014.

LOCATELLI, A.; SANTOS, K. F.; ZOCH, A. N.. Unidade de ensino potencialmente significativa para o ensino de química orgânica, abordando atemática dos agrotóxicos. Areté: Revista Amazônica de Ensino de Ciências, v. 9, n. 18, p. 158-172, 2016.

LUCKESI, C.C. O que é mesmo o ato de avaliar a aprendizagem? Revista Pátio, v.4, n.12, p. 6-11, 2000.

MARTINS, L.; DIONOR, G. A.; FERRAZ, L. V.; SOUZA, H. S. Doença de Chagas a partir de questões sociocientíficas na educação em saúde. In: CONRADO, D. M.; NUNES-NETO, N. (org.). Questões sociocientíficas: fundamentos, propostas de ensino e perspectivas para ações sociopolíticas. Salvador: EDUFBA, 2018, p. 213-229.

MELLO, L. F.; FONSECA, E. M.; DUSO, L. Agrotóxicos no ensino de química: proposta contextualizada através de um jogo didático. Revista Eletrônica Ludus Scientiae, v. 02, n. 01, p. 76-90, jan./jun., 2018.

REIS, P. Controvérsias sócio-científicas: discutir ou não discutir?: percursos de aprendizagem na disciplina de ciências da Terra e da vida. 2004. 488 f. Tese (Doutorado em Educação) - Faculdade de Ciências, Universidade de Lisboa, Lisboa (Portugal), 2004.

SADLER, T. D.; FOULK, J. A.; FRIEDRICHSEN, P. J. Evolution of a model for socioscientific issue teaching and learning. International Journal of Education in Mathematics, Science and Technology, v. 5, n. 2, p. 75-87, 2017.

SADLER, T. D.; ZEIDLER, D. L. The morality of socioscientific issues: construal and resolution of genetic engineering dilemmas. Science Education, v. 88, n. 1, p. 4-27, 2004. 
SANTOS, J.; CONRADO, D. M.; NUNES-NETO, N. Poluição hídrica: uma questão sociocientífica para abordar ética ambiental no ensino fundamental de ciências. In: CONRADO, D. M.; NUNES-NETO, N. (org.). Questões sociocientíficas: fundamentos, propostas de ensino e perspectivas para ações sociopolíticas. Salvador: EDUFBA, 2018, p. 191-211.

TARAS, M. De volta ao básico: definições e processos de avaliação. Práxis Educativa, v.5, n.2, p.123-130, 2010.

TEIXEIRA, P. J. M.; PASSOS, C. C. M. Um pouco da teoria das situações didáticas (tsd) de Guy Brousseau. Zetetike, v. 21, n. 1, p. 155-168, 2013.

WALKER, K. A.; ZEIDLER, D. L. Promoting discourse about socioscientific issues through scaffolded inquiry. International Journal of Science Education, v. 29, n. 11, p. 1387-1410, 2007.

ZEIDLER, D. L.; NICHOLS, B. H. Socioscientific issues: Theory and practice. Journal of Elementary Science Education, v. 21, n. 2, p. 49, 2009.

Recebido em abril de 2021.

Aprovado em outubro de 2021. 
APÊNDICE A - Roteiro para pesquisa

\begin{tabular}{|l|l|}
\hline Integrantes da equipe: & \\
\hline Agrotóxico a ser pesquisado: & $\begin{array}{l}\text { Sugestão de agrotóxicos para pesquisa (são alguns dos mais } \\
\text { utilizados no Brasil): } \\
\text { Glifosato / Paraquate / 2,4-D / Piraclostrobina / Acefato / } \\
\text { Atrazina / Mancozebe }\end{array}$ \\
\hline Estrutura química: & \\
\hline Em que tipos de lavouras são utilizados? & \\
\hline Onde são proibidos? & \\
\hline Onde são permitidos? & \\
\hline $\begin{array}{l}\text { Existe algum projeto da empresa que } \\
\text { produto responsabilidade pelo uso desse }\end{array}$ & \\
\hline Outras informações relevantes & \\
\hline
\end{tabular}

